\title{
THE ELECTROENCEPHALOGRAPHIC DIAGNOSIS OF MANIFEST AND LATENT 'DELIRIUM' WITH PARTICULAR REFERENCE TO THAT COMPLICATING HEPATIC CIRRHOSIS
}

\author{
BY
}

\author{
JOHN LAIDLAW' ${ }^{1}$ and A. E. READ ${ }^{2}$
}

From the Department of Medicine, the Postgraduate Medical School, Ducane Road, London

In a previous paper in this journal (Laidlaw, 1959), one of us discussed the potential value of assessing the generalized electroencephalographic (EEG) abnormalities which were found in those general medical disorders which did not affect the brain primarily, and described a visual method of expressing these abnormalities in the form of frequency patterns. Although it was felt that there was a place for this simple method, particularly in small EEG departments, it was admitted that it took time, was dependent on the experience of the observer, and provided only a limited amount of information. It was proposed that future work should be based on some form of automatic analysis.

This paper explains the system which was developed for quantifying and grading information about the rhythmic background activity of the EEG, whether normal or abnormal, obtained from a modified and simplified electronic waveform analyser, and describes the application of this system to a particular clinical problem.

The system of analysis has been applied to a variety of those general medical conditions in which the EEG is affected and it is clear that the changes which occur are not specific to any particular condition. One may postulate that there is a disorder of the metabolism of deeply placed structures of the brain. The EEG follows a fairly well-defined series of changes over a continuum from normal consciousness to deep coma (Laidlaw, 1959). There is at first a gradual reduction in the frequency of the rhythmic activity which may be preceded, accompanied, or immediately followed by a partial failure of alerting conditions to reduce or maintain the reduction of this rhythmic activity. Later, when the background rhythms have fallen to between 4 and 6 cycles per second (c/s) larger slower waves

Present address: ${ }^{1}$ Department of Surgical Neurology, the Royal Infirmary and Western General Hospital, Edinburgh. ${ }^{2}$ Department of Medicine, Bristol University.

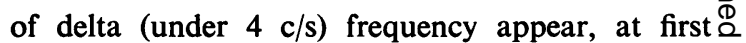
occasionally and usually anteriorly, but gradually increasing in frequency and distribution until they $\vec{P}$ come to dominate the record from all areas.

Certain patients with hepatic cirrhosis form an $\vec{\omega}$ important group in which these changes occur. They are liable to episodes of confusion or alteration of consciousness (Adams and Foley, 1953) which we will term 'delirium'. A factor in the + production of this delirium is the absorption of $\vec{c}$ nitrogenous products from the gut (Sherlock, 1958., which are either inadequately detoxicated by damaged liver and/or reach the brain in abnorm 1 I quantities through collateral portal systemic venous channels. We will use the term 'encephalopaths' to describe not the acute episode of delirium bet the underlying state which makes certain patients liable to develop such episodes. It has be $\overrightarrow{0}$

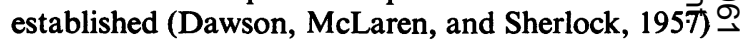
that reducing the nitrogen content of the bowel by 0 low-protein feeding or by sterilization with an antibiotic such as neomycin is useful for the acute phase, the delirium, and also reduces the liability for such a phase to develop on provocation, that is, $\frac{Q}{\mathbb{Q}}$

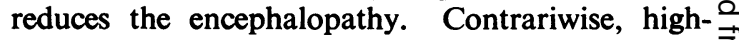
protein feeding or the addition of nitrogen-containing compounds, such as ammonium chloride, makes delirium worse and more likely to develop: it increases the encephalopathy.

It is important for the clinician to know whether or not a patient with hepatic cirrhosis suffers from? encephalopathy and, if so, to what extent, that is, $\frac{5}{3}$ under what conditions of diet or treatment he may. be at particular risk of developing delirium. In severe cases of encephalopathy there may be permanent clinical, psychological, or electroencephalo- $\frac{\text { ? }}{7}$ graphic abnormalities, but in these cases the diag- $\rightarrow$ nosis is seldom in doubt and the electroencephalographic evidence is merely confirmatory. In those milder cases where the diagnosis is doubtful the EEG, while providing very early evidence of 0 
developing delirium (Read, Laidlaw, Haslam, and Sherlock, 1959), may be unable to detect a latent encephalopathy.

The technique to be described is based on provoking delirium in patients with hepatic encephalopathy and in using the EEG changes produced by this provocation as an index sufficiently sensitive to enable the provocation to be kept well below the level at which the patient would be exposed to the slightest risk.

Morphine was chosen as the provocative agent because it has been reported as producing delirium in patients with hepatic disease (Fagin and Thompson, 1944; Murphy, Chalmers, Eckhardt, and Davidson, 1948). Preliminary tests showed that small doses were perfectly safe. It has been reported as producing in normal subjects no EEG changes other than those of drowsiness or sleep (Greville and Heppenstall, 1950; Wikler, 1954; Andrews, 1941).

As the normal subject passes from full wakefulness through drowsiness to light sleep the EEG changes are well established (Davis, Davis, Loomis, Harvey, and Hobart, 1938; Dement and Kleitman, 1957) and are different from those of increasing delirium. Occasionally interpretation is difficult when drowsiness is a feature of the delirium and the EEG changes of the two conditions coexist. The findings to be reported suggest that in all subjects the changes produced by morphine are nearer to those of increasing delirium than of increasing drowsiness. However, it is not the purpose of this paper to discuss the differentiation between the sleep-wakefulness and delirium continua of EEG change, and such a differentiation is unnecessary since we are concerned with the differential EEG responses between patients and in the same patient under various conditions. We are satisfied, however, that the EEG changes produced by morphine are sufficiently similar to those produced by the early stages of delirium for the criteria of such changes to be directly compared.

\section{General EEG Method}

All records were made on an eight-channel Ediswan machine with filters fcr $75 \mathrm{c} / \mathrm{s}$ and time constant at $0.3 \mathrm{sec}$., and were analysed with a B.N.I. low frequency waveform analyser produced and specially adapted by Faraday Electronic Instruments Ltd. This analyser consisted essentially of 12 resonant circuits with centre frequencies at 2, 3, 4 and so on up to $12 \mathrm{c} / \mathrm{s}$ with $50 \%$ reduction $\pm \frac{1}{2} \mathrm{c} / \mathrm{s}$ and at $17 \mathrm{c.p.s}$. with $50 \%$ reduction $\pm 1 \frac{1}{2} \mathrm{c} / \mathrm{s}$. The output from these circuits was lead to storage capacitors whose charge during a chosen epoch was read off from a meter in arbitrary units: these readings will be referred to as 'activity at such and such a frequency'. The outputs from those six circuits which showed the greatest activity were also lead back to an intermediate stage of the Ediswan EEG machine to give a direct write out of six channels of waves as they occurred at each of these frequencies (Fig. 1). The numerical value of the arbitrary units depends on the gains and adjustment of the analyser but is irrelevant since all the derived measures are proportions. It is convenient to adjust the analyser so that an input of 1 volt from a low-frequency sine wave oscillator gives a peak calibration reading of 10 microamps. It is important to adjust the gains on the analyser so that the maximum reading obtained lies within that part of the scale which is linear. The errors due to fluctuations in the apparatus lie well under $5 \%$ and may be ignored.

Two channels of primary EEG were recorded from the antero- and posterc-lateral aspects of the non-dominant hemisphere. The activity from the posterolateral channel was fed to the waveform analyser. For each record 10 epochs, each of 15 seconds, were analysed. There were four types of epoch:-

S. 1-5. From 15 to $30 \mathrm{sec}$. after shutting the eyes.

O. 1, 2. From 15 to $30 \mathrm{sec}$. after opening the eyes. The patient lay on a couch in a dimly lit room and his gaze was directed towards a blackboard $2 \mathrm{ft}$. square and $6 \mathrm{ft}$. away on which were 100 small light bulbs in 10 rows of 10 , centred 2 in. apart. No lights were switched on.

L. 1, 2. From 15 to $30 \mathrm{sec}$. after opening the eyes. As in O. 1, 2, but with 20 to 30 lights switched on to form a pattern.

Lc. From 0 to $15 \mathrm{sec}$. after opening the eyes. A different pattern of lights was presented on the board and the patient had been instructed to start to count the lights as soon as he opened his eyes and to call out the answer as soon as he had finished. The number of lights was adjusted to the patient so that he took rather longer than 15 seconds to count them.

The epochs were always arranged in the following order: S.1, O.1, L.1, S.2, O.2, L.2, S.3, S.4, S.5, and Lc. For each 15-second epoch the activity at each frequency was read off the analyser meter. A typical epoch reading might be:-

Cycles per second-

$$
\begin{array}{llllllllllll}
2 & 3 & 4 & 5 & 6 & 7 & 8 & 9 & 10 & 11 & 12 & 17
\end{array}
$$

Activity in arbitrary units for S.1-

$$
\begin{array}{llllllllllll}
5 & 5 & 6 & 7 & 7 & 10 & 22 & 42 & 16 & 8 & 4 & 4
\end{array}
$$

From this data the following calculations were derived.

Dominant Frequency-The frequency at which there is most activity \pm a skew figure which is obtained by dividing the difference between the sums of the activities at the two frequencies above and below the main frequency by the activity at this frequency and multiplying by 100 . In the example above the dominant frequency for $\mathrm{S} .1$ would be:

$$
9-\frac{(10+22)-(16+8)}{42} \cdot 100=9-19
$$

Change in dominant frequency is themexpressed in units. It has been found that if the dor frequency lies midway between two frequencio of the usually 


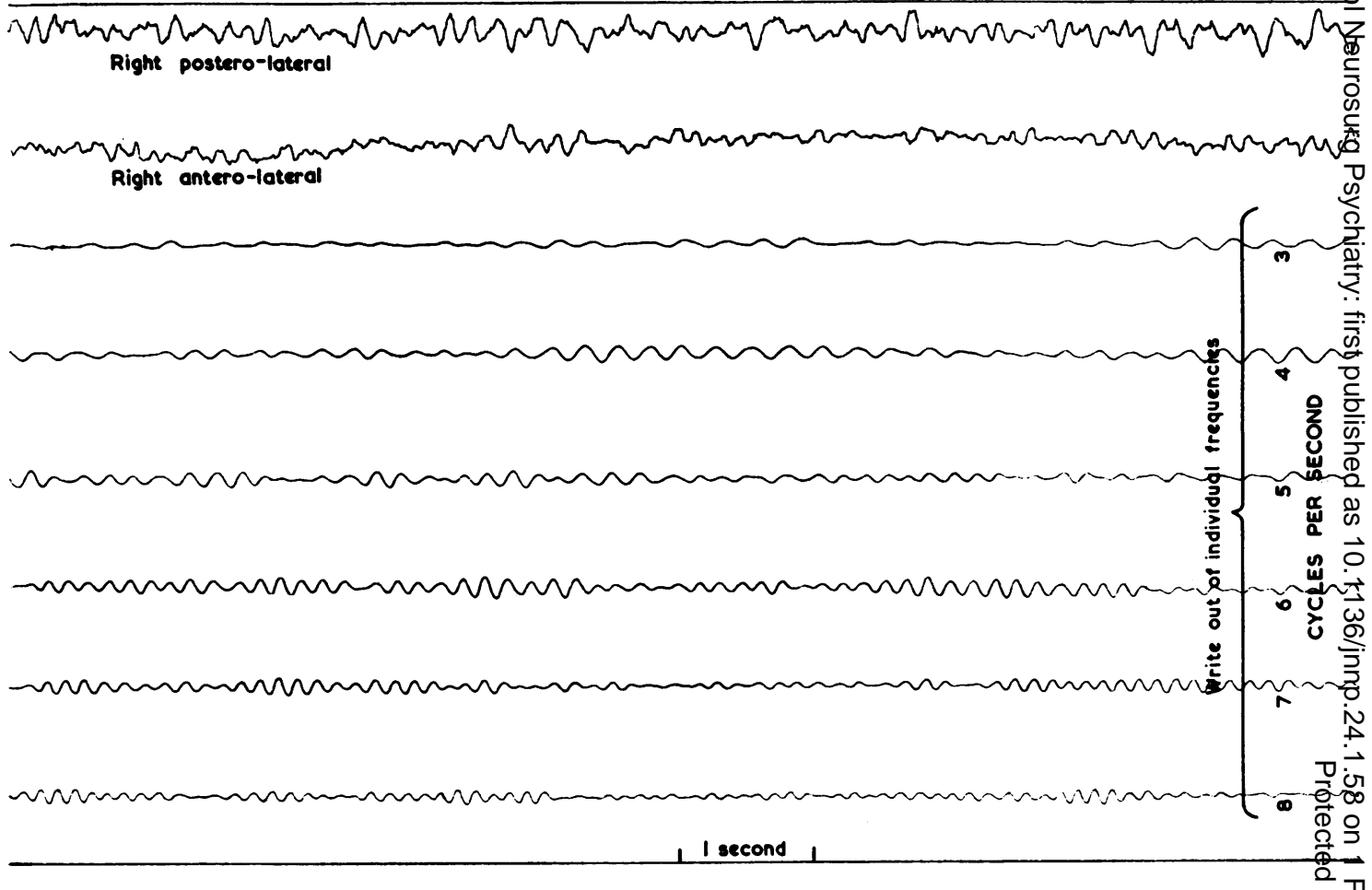

FIG. 1.-Case 8 with known encephalopathy. Moderate generalized abnormality in pre-morphine record. Channels 1 and 2 show the pringr $\Phi$ EEG tracing from the postero- and antero-lateral aspects of the right hemisphere. Channels 3-8 show the write-out from the analysef of waves as individual frequencies from 3 to $8 \mathrm{c} / \mathrm{s}$.

lies roughly 75 units \pm with respect to the lower or higher frequency. Therefore, in making calculations of frequency shift a figure of 150 units has been allowed for a full cycle per second. Thus a change from a frequency of $9+19$ to $8-32$ is measured as $19+150+32$ $=201$ units. Dominant frequencies are calculated for each $\mathrm{S}$ epoch and for the mean of the $5 \mathrm{~S}$ epochs.

Rhythmic Activity (RA).-The sum in arbitrary units of the activities at the frequency with the most activity and the two frequencies on either side. In the example above: RAS. $1=42+(10+22)+(16+8)=98$. These calculations are made for each epoch with the eyes shut (RAS 1-5), open (RAO 1, 2), while looking at the light pattern (RAL 1, 2), and while counting the lights (RALc), and for the means of the shut (RAS), open (RAO), and lights (RAL) epochs.

From these figures it is possible to measure numerically changes between epochs, records, and patients in terms of dominant frequency and rhythmic activity under different conditions.

Two types of record are not suitable for purely numerical measurement and are best assessed by combining analysis with inspection of the direct write-out of the analysed frequencies and the visual method previously described (Laidlaw, 1959).
Records Dominated by Discontinuous Delta Activity. Electronic analysis of such activity is apt to be un reliable since the tuned circuits respond to rhythmio activity rather than to occasional waves (Burch, 1959) and, since activity measured on the analyser is the product of number of waves and amplitude, it is possible to get spurious high readings at low frequencies due t\& underlying low amplitude background wobble or artefact.

Desynchronized Records Containing Little Rhythmie Activity.-The presence or absence of change is bes. assessed from the direct write-out of what activity there may be.

For descriptive purposes EEG generalized abnor malities may be classified according to the following criteria:-

Severe abnormality.. dominant frequency under $4 \mathrm{c} / \$$ (within delta range).

Moderate abnormality..dominant frequency betwee 9 4 and $6 \mathrm{c} / \mathrm{s}$.

Mild abnormality..dominant frequency between and $7 \mathrm{c} / \mathrm{s}$.

Borderline. . dominant frequency between 7 and $8 \mathrm{c} / \mathrm{s} \sim$

Normal..dominant frequency between 8 and $13 \mathrm{c} / \AA$ (within alpha range). 
In any large series of controls it will be found that most records will be normal, a number borderline, and a few will show a mild or possibly even a moderate abnormality (Brazier and Finesinger, 1944). This method of classification is of some value for describing single records but when there is little or no clinical evidence of delirium, the EEG is likely to be normal or borderline, perhaps sometimes showing a mild abnormality, and a single record has little diagnostic value. However, it is at this stage that the EEG is very sensitive to alterations in cerebral metabolism and the measurement of EEG changes may be of great value whether expressed quantitatively in terms of dominant frequency and RAO ( $\mathrm{L}$ or $\mathrm{Lc}$ ), or in terms of grades of change as are described later.

\section{Clinical Application}

Problem.-To contrast the EEG responses to small doses of morphine in patients with and without hepatic encephalopathy and the responses in patients with hepatic encephalopathy under different conditions of diet and treatment and to develop therefrom a method of assessing in doubtful cases the presence and extent of encephalopathy.

\section{Method}

Fifty-nine patients (Table I) were classified clinically as follows:-

Group E.-These are patients with hepatic cirrhosis who have had established episodes of delirium, or alteration of consciousness, sometimes referred to as hepatic 'coma' or 'pre-coma', such episodes being directly attributable to liver disease and being characterized by confusion, alteration of consciousness, sometimes increased tendon reflexes, 'flapping tremor', foetor hepaticus and, almost invariably, severely abnormal EEGs. These patients are considered to suffer from known encephalopathy with a tendency to develop delirium. Factors which tend to provoke delirium include infections, drugs, gastro-intestinal haemorrhage, and deterioration in liver function. The group is a heterogeneous one with patients requiring widely varying degrees of provocation.

Group C.-The control group consisted of patients without liver disease, termed controls, and those with various diseases of the liver said to have no encephalo- pathy because there had never been an episode suggesting delirium and there was no reason why such an episode should develop.

Group D.-These were patients with hepatic cirrhosis considered to have doubtful encephalopathy. This group includes, on the one hand, patients who, because of such factors as the state of liver function, age, or extent of collateral circulation, are considered as possibly liable to develop delirium, and, on the other, those who have a history of episodes suggestive of but not definitely shown to be hepatic delirium.

In 112 tests on 64 patients, EEGs were recorded immediately before and three hours after varying doses of morphine. Of these, eight tests have been excluded as follows: four tests (two patients) because the associated EEG changes of drowsiness made assessment impossible and four tests (three patients) because there were EEG abnormalities presumed to be due to another condition later diagnosed (disseminated sclerosis, epilepsy, and Hodgkin's disease). Table I shows the distribution of the remaining 104 tests on 59 patients (40 female, 19 male, aged from 19 to 76 years) according to clinical classification and dose of morphine. There were eight 'dummy' morphine tests in which no morphine was given.

The general EEG method already described was used. For the sake of simplicity and in order that the results for the whole series might be comparable, only two measures of change were calculated: units of dominant frequency change and percentage change in rhythmic activity with the eyes open (RAO). Deterioration, considered as reduction in dominant frequency and percentage increase in RAO, is expressed numerically and in terms of the following arbitrarily chosen grades:-

\section{Grades of Change}

Grade 4.-The appearance in the second record of high-amplitude delta waves which were not present in the first and which were sufficiently prominent to dominate the record.

Grade 3.-A reduction in dominant frequency of 150 units $(1 \mathrm{c} / \mathrm{s})$ or more with an increase in RAO of $25 \%$ or more.

Grade 2.-A reduction in dominant frequency of $50-149$ units with an increase in RAO of $25 \%$ or more.

TABLE I

DISTRIBUTION OF TESTS ACCORDING TO DOSE OF MORPHINE AND CLINICAL GROUPING OF PATIENTS

\begin{tabular}{|c|c|c|c|c|c|c|c|c|c|c|c|c|}
\hline \multirow[b]{2}{*}{$\begin{array}{c}\text { Patient } \\
\text { Classification }\end{array}$} & \multirow[b]{2}{*}{$\begin{array}{l}\text { Clinical } \\
\text { Group }\end{array}$} & \multirow[b]{2}{*}{$\begin{array}{l}\text { No. of } \\
\text { Patients }\end{array}$} & \multirow[b]{2}{*}{$\begin{array}{l}\text { No. of } \\
\text { Tests }\end{array}$} & \multirow{2}{*}{$\begin{array}{c}\text { Nu- } \\
\text { merical } \\
\text { Analysis } \\
\text { Only }\end{array}$} & \multicolumn{3}{|c|}{$\begin{array}{l}\text { Dose of Morphine } \\
\text { (mg.) }\end{array}$} & \multicolumn{5}{|c|}{ Grading of Pre-morphine Record } \\
\hline & & & & & $\mathbf{0}$ & 8 & 16 & Normal & Borderline & $\begin{array}{c}\text { Mild } \\
\text { Ab- } \\
\text { normality }\end{array}$ & \begin{tabular}{|c|} 
Moderate \\
Ab- \\
normality
\end{tabular} & $\begin{array}{c}\text { Severe } \\
\text { Ab- } \\
\text { normality }\end{array}$ \\
\hline \multirow{3}{*}{$\begin{array}{l}\text { Controls } \\
\text { No encephalopathy } \\
\text { Doubtful } \\
\text { encephalopathy } \\
\text { Certain } \\
\text { encephalopathy }\end{array}$} & $\underset{\mathbf{C}}{\mathbf{C}}$ & $\begin{array}{r}8 \\
14\end{array}$ & $\begin{array}{r}8 \\
17\end{array}$ & $\begin{array}{r}5 \\
10\end{array}$ & $\begin{array}{l}0 \\
4\end{array}$ & $\begin{array}{l}3 \\
9\end{array}$ & $\begin{array}{l}5 \\
4\end{array}$ & $\begin{array}{r}8 \\
15\end{array}$ & $\begin{array}{l}\mathbf{0} \\
\mathbf{2}\end{array}$ & $\begin{array}{l}0 \\
0\end{array}$ & $\begin{array}{l}\mathbf{0} \\
\mathbf{0}\end{array}$ & $\begin{array}{l}\mathbf{0} \\
\mathbf{0}\end{array}$ \\
\hline & D & 20 & 41 & 36 & 3 & 32 & 6 & 32 & 5 & 3 & 0 & 0 \\
\hline & $\mathbf{E}$ & 17 & 38 & 29 & 1 & 34 & 3 & 17 & 8 & 6 & 7 & $\mathbf{0}$ \\
\hline Total & & 59 & 104 & 80 & 8 & 78 & 18 & 72 & 15 & 9 & 7 & $\mathbf{0}$ \\
\hline
\end{tabular}




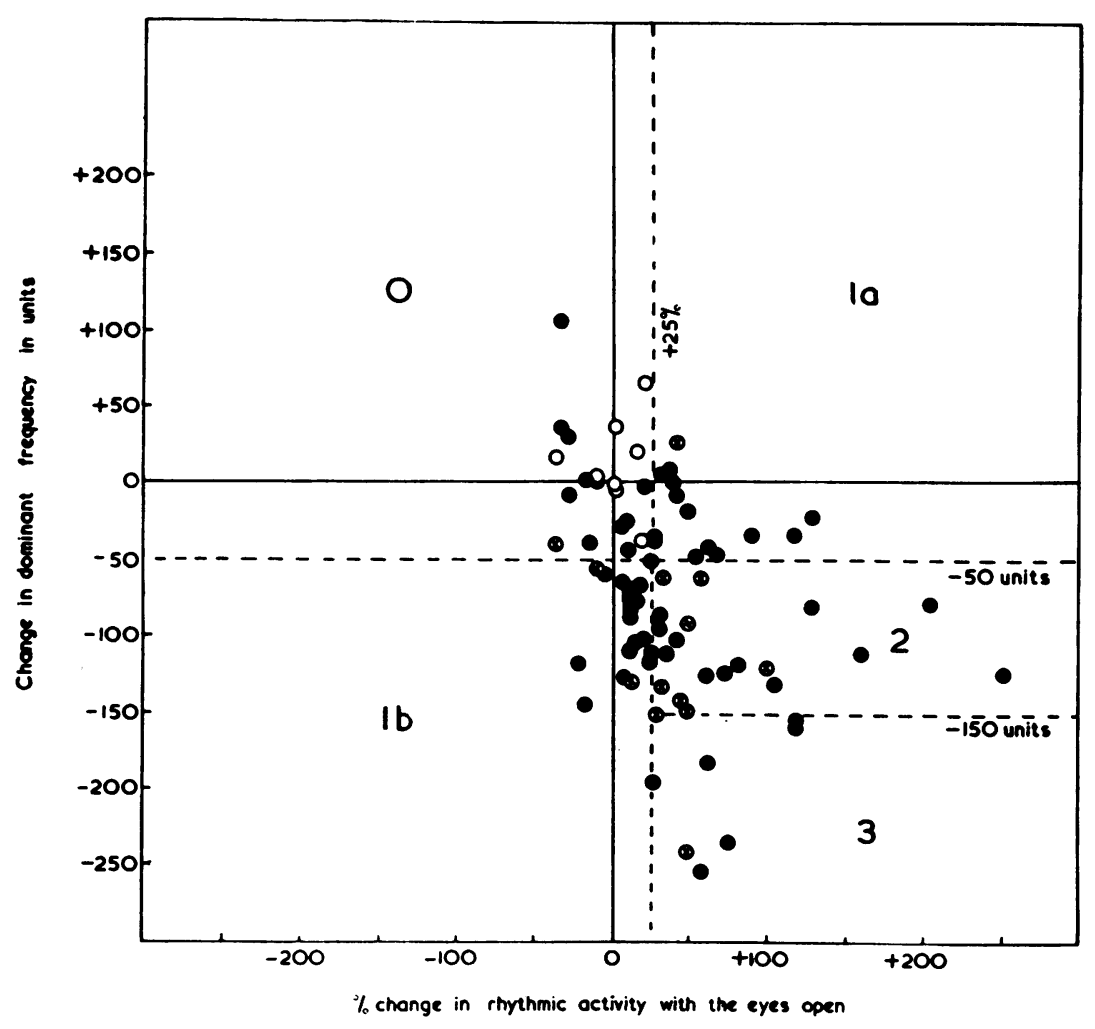

FIG. 2.-Results in the 80 morphine tests in which the EEG changes were expressed numerically. Each point represents unit change in dominant frequency plotted against percentage change in rhythmic activity with the eyes open for one test. $0=$ no morphine, $0=8 \mathrm{mg}$., $\oplus=16 \mathrm{mg}$. morphine. The five areas into which the graph is divided correspond to grades of change $0,1 \mathrm{a}, 1 \mathrm{~b}, 2$, and 3 .

Grade 1b.-A reduction in dominant frequency of 50-149 units without an increase in RAO of $25 \%$ or more.

Grade 1a.-An increase in RAO of $25 \%$ or more without a reduction in dominant frequency of 50 units or more.

Grade 0.-Records which do not show the numerical changes above or which, if not assessed purely quantitatively, show no change considered as significant.

Grade 1 has been subdivided because it was found that the first evidence of deterioration might be either increase in RAO or reduction in dominant frequency.

In certain cases (Table III) the tests were repeated under different conditions which are referred to as follows:-

P.-After three days' treatment with neomycin, 1 g. t.d.s., usually on $40 \mathrm{~g}$. protein diet

Q.-After a $40 \mathrm{~g}$. protein diet for at least seven days

R.-After a normal ward diet (about $70 \mathrm{~g}$. protein) for at least seven days

S.-After a protein diet of 100 to $120 \mathrm{~g}$. for at least seven days
T.-After ammonium chloride, 2 g. t.d.s. for three days, usually on a high-protein diet.

All comparisons between records are made in the direction of expected deterioration, e.g., $\mathrm{P}-\mathbf{R}=$ changeo between neomycin régime and normal diet. The addition of ' $m$ ' denotes a post-morphine EEG: thus $\vec{F}$ $\mathbf{R}$-Tm represents the EEG change between the premorphine record on ward diet and the post-morphine record after three days on ammonium chloride.

\section{Results}

To the right of Table I is shown the classification of the pre-morphine records. The seven moderately abnormal records were made during repeated tests on two patients in group E. It will be seen that the great majority $(84 \%)$ of records are normal or borderline and that it would not be possible to decide from a single record whether or not a patient suffered from encephalopathy, i.e., to place a․ group D patient in either group $\mathrm{E}$ or $\mathrm{C}$.

In Fig. 2 unit change in dominant frequency is plotted against percentage change in RAO. It will 
TABLE II

EEG DETERIORATION- EXPRESSED IN GRADES, PRODUCED BY DIFFERENT DOSES OF MORPHINE IN CLINICAL GROUPS C, D, AND E

\begin{tabular}{|c|c|c|c|c|c|c|c|c|c|}
\hline \multirow{2}{*}{ Patient Classification } & \multirow{2}{*}{ Clinical Group } & \multirow{2}{*}{$\begin{array}{c}\text { Dose of Morphine } \\
\text { (mg.) }\end{array}$} & \multirow{2}{*}{$\begin{array}{l}\text { No. of } \\
\text { Tests }\end{array}$} & \multicolumn{6}{|c|}{ Grade of Change } \\
\hline & & & & 0 & $1 \mathbf{a}$ & $1 b$ & 2 & 3 & 4 \\
\hline $\begin{array}{l}\text { Controls and no encephalopathy } \\
\text { Certain encephalopathy } \\
\text { Doubtful encephalopathy } \\
\text { Controls and no encephalopathy }\end{array}$ & $\begin{array}{l}\mathbf{C} \\
\mathbf{E} \\
\mathbf{D}\end{array}$ & $\begin{array}{r}8 \\
8 \\
8 \\
16\end{array}$ & $\begin{array}{r}12 \\
34 \\
32 \\
9\end{array}$ & $\begin{array}{r}11 \\
4 \\
4 \\
4\end{array}$ & $\begin{array}{r}0 \\
3 \\
10 \\
1\end{array}$ & $\begin{array}{l}0 \\
9 \\
7 \\
1\end{array}$ & $\begin{array}{l}1 \\
8 \\
7 \\
3\end{array}$ & $\begin{array}{l}\mathbf{0} \\
\mathbf{4} \\
\mathbf{3} \\
\mathbf{0}\end{array}$ & $\begin{array}{l}\mathbf{0} \\
\mathbf{6} \\
1 \\
\mathbf{0}\end{array}$ \\
\hline
\end{tabular}

be seen that irrespective of dose and clinical grouping (not shown on this figure) the general effect of morphine is to produce a reduction in dominant frequency and an increase in RAO, considered as indices of EEG deterioration. No particular significance may be attached to the relative positions of the $8 \mathrm{mg}$. and $16 \mathrm{mg}$. points since the larger dose was given to less severely affected patients and was discontinued during the investigation.

Table II contrasts the grade of change produced by different doses given to different clinical groups. It refers to tests and not to patients. The four grade 0 tests in group $\mathrm{E}$ patients were repeated under different conditions and gave positive responses. The one test in group $\mathrm{C}$ graded 2 was on a patient with a peptic ulcer who at the time was being treated with phenobarbitone, grain $1 \frac{1}{2}$ t.d.s., and it may be that the effect of the large dose of phenobarbitone and the small dose of morphine was comparable to that of $16 \mathrm{mg}$. of morphine. The results in this table show that patients in group $\mathrm{E}$ responded more vigorously to $8 \mathrm{mg}$. of morphine than do those in group $\mathrm{C}$; that this differential effect is quantitative not absolute, because some patients in group $\mathrm{C}$ show a response to the larger dose; some patients in group $\mathrm{E}$ may, under certain conditions, show a grade 0 response, although under other conditions they show a greater one; and the division into grades is arbitrary and there are many points in the grade $\mathbf{0}$ area of Fig. 2 which show an appreciable reduction in frequency and increase in RAO.

On the whole patients in group $D$ show a response intermediate between those in groups $\mathrm{C}$ and $\mathrm{E}$. This is the group in which a diagnostic test is required and although a large response would be very suggestive of encephalopathy a smaller one would be equivocal.

The dose of $16 \mathrm{mg}$. was stopped during the investigation, first, because of the poor differentiation between groups $\mathrm{C}$ and $\mathrm{E}$, and secondly, because some group $\mathrm{E}$ patients showed a very marked EEG response to this dose. Although they were not affected clinically it was felt that the larger dose

TABLE III

\begin{tabular}{|c|c|c|c|c|c|c|c|c|c|}
\hline \multirow{3}{*}{$\begin{array}{l}\text { Clinical } \\
\text { Group }\end{array}$} & \multirow{3}{*}{$\begin{array}{c}\text { Patient } \\
\text { No. }\end{array}$} & \multicolumn{4}{|c|}{ Differential Morphine Tests } & \multicolumn{4}{|c|}{ Diet, Treatment, and Additive Morphine Tests } \\
\hline & & \multirow{2}{*}{$\begin{array}{l}\text { Records } \\
\text { Compared }\end{array}$} & \multicolumn{2}{|c|}{ Numerical Change } & \multirow{2}{*}{ Grade } & \multirow{2}{*}{$\begin{array}{l}\text { Records } \\
\text { Compared }\end{array}$} & \multicolumn{2}{|c|}{ Numerical Change } & \multirow{2}{*}{ Grade } \\
\hline & & & $\begin{array}{l}\text { Dominant } \\
\text { Frequency }\end{array}$ & $\%$ RAO & & & $\begin{array}{l}\text { Dominant } \\
\text { Frequency }\end{array}$ & $\%$ RAO & \\
\hline $\begin{array}{l}\mathrm{E} \\
\mathrm{E} \\
\mathrm{E} \\
\mathrm{E} \\
\mathrm{E} \\
\mathrm{E} \\
\mathrm{E} \\
\mathrm{E} \\
\mathrm{E} \\
\mathrm{E}\end{array}$ & $\begin{array}{r}1 \\
1 \\
8 \\
8 \\
13 \\
13 \\
33 \\
33 \\
36 \\
36 \\
40 \\
40 \\
40 \\
41 \\
41 \\
43 \\
43 \\
44 \\
44 \\
52 \\
52\end{array}$ & 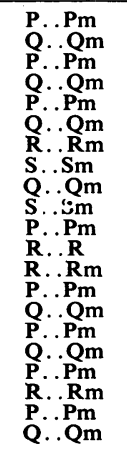 & 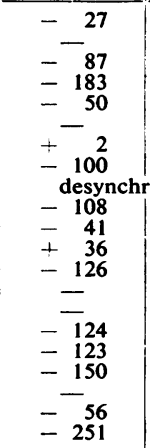 & $\begin{array}{lr}+ & 7 \\
+ & -13 \\
+ & 62 \\
+ & 25 \\
+ & 38 \\
+ & 38 \\
+ & 42 \\
\text { ized } & 35 \\
+ & 11 \\
+ & 2 \\
+ & 61 \\
+ & 2 \\
+ & 56 \\
+ & 6 \\
+ & 250 \\
+ & 49 \\
- & 2 \\
- & 58\end{array}$ & $\begin{array}{l}0 \\
4 \\
1 \mathrm{~b} \\
3 \\
2 \\
4 \\
1 \mathrm{a} \\
2 \\
0 \\
2 \\
0 \\
0 \\
2 \\
4 \\
4 \\
1 \mathrm{~b} \\
2 \\
3 \\
4 \\
1 \mathrm{~b} \\
3\end{array}$ & 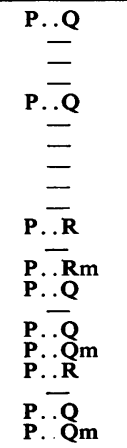 & $\begin{array}{l}-{ }^{14} \\
= \\
- \\
- \\
= \\
= \\
- \\
-\quad 49 \\
-175 \\
-\quad 56 \\
-\quad 83 \\
=206 \\
-177 \\
-69 \\
-182\end{array}$ & $\begin{array}{c}-{ }^{27} \\
- \\
+{ }^{-} \\
= \\
= \\
- \\
+{ }^{2} \\
+105 \\
-19 \\
-\quad 50 \\
+75 \\
+80 \\
+\quad 12 \\
+78\end{array}$ & $\begin{array}{l}0 \\
\overline{-} \\
\overline{1} \\
\bar{a} \\
\bar{a} \\
\overline{-} \\
\overline{-} \\
1 \mathrm{a} \\
3 \\
\frac{3}{1} \mathrm{~b} \\
1 \mathrm{~b} \\
3 \\
\frac{3}{0} \\
3\end{array}$ \\
\hline $\mathbf{C}$ & $\begin{array}{l}51 \\
51 \\
51\end{array}$ & $\begin{array}{l}\text { R. Rm } \\
\text { S..Sm } \\
\text { T..Tm }\end{array}$ & $\begin{array}{l}\text { desynch } \\
\text { desynch } \\
\text { desynchr }\end{array}$ & $\begin{array}{l}\text { nized } \\
\text { nized } \\
\text { hized }\end{array}$ & $\begin{array}{l}\mathbf{0} \\
\mathbf{0} \\
\mathbf{0}\end{array}$ & $\begin{array}{l}\text { R..S } \\
\mathbf{R} . . \mathrm{Sm} \\
\mathbf{R} . \mathbf{T} \text {, } \\
\mathbf{R} . \mathrm{Tm}\end{array}$ & $\begin{array}{l}\text { desync } \\
\text { desync } \\
\text { desync }\end{array}$ & $\begin{array}{l}\text { nized } \\
\text { nized } \\
\text { nized }\end{array}$ & $\begin{array}{l}\mathbf{0} \\
\mathbf{0} \\
0\end{array}$ \\
\hline
\end{tabular}



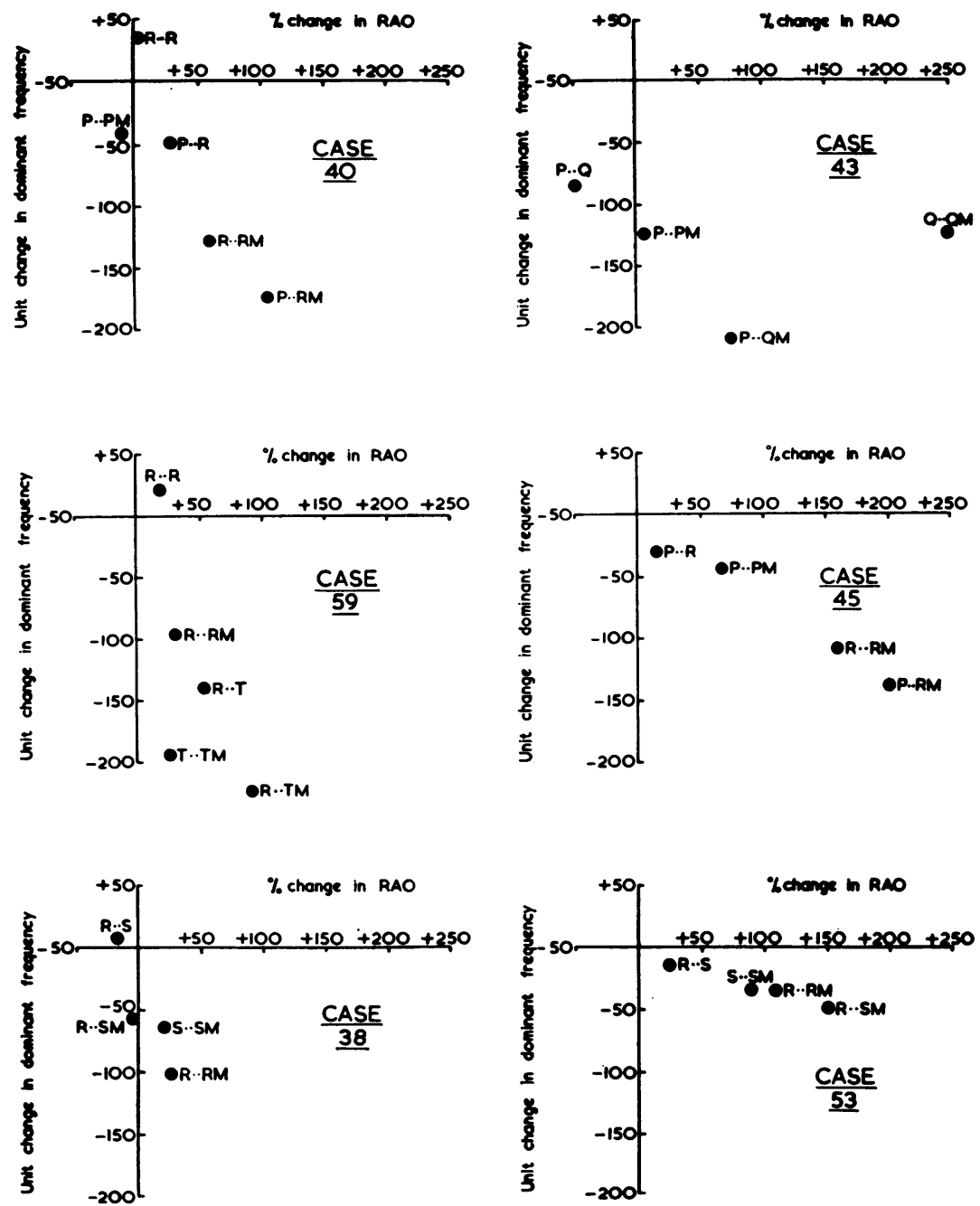

Fig. 3.-Graphic representation, similar to that in Fig. 2, of deterioration in EEG as a result of morphine and changes in diet and treatment (see also Tables III and IV). Cases 40 and 43, clinical group E; Cases 59, 45, 38, and 53 group D. The EEG tests support the diagnosis of hepatic encephalopathy in Cases 59 and 45, are against it in Case 38, and provide some evidence in favour in Case 53.

might be dangerous. The test dose of $8 \mathrm{mg}$. proved harmless in the 66 tests on group D and E patients.

From the results so far presented it may be postulated that the EEG response to morphine is related to the presence and to the degree of encephalopathy. Alterations in diet or treatment (conditions P, Q, R, S, or T) affect encephalopathy. If the above hypothesis is correct, such alterations should produce a differential response to morphine. The left side of Table III shows the results of these differential morphine tests in 11 patients, 10 from group $\mathrm{E}$ and one from group $\mathrm{C}$, expressed in grades of change, and, except for desynchronized records and those showing grade 4 change, numerically Each group $\mathrm{E}$ patient showed a positive differentia test, a greater response on going from $P$ to $Q$ to $\mathbf{R}$ to $\mathbf{S}$. Ammonium chloride was not given to these patients. The one patient in group $C$ showed no such change. The results for patients 40 and 43 are shown graphically in Fig. 3. A dummy morphing test, $R-R$, is shown for patient 40 .

In some patients with hepatic encephalopath EEG deterioration may be produced by diet changes alone. The effect which, like the response to mort 
TABLE IV

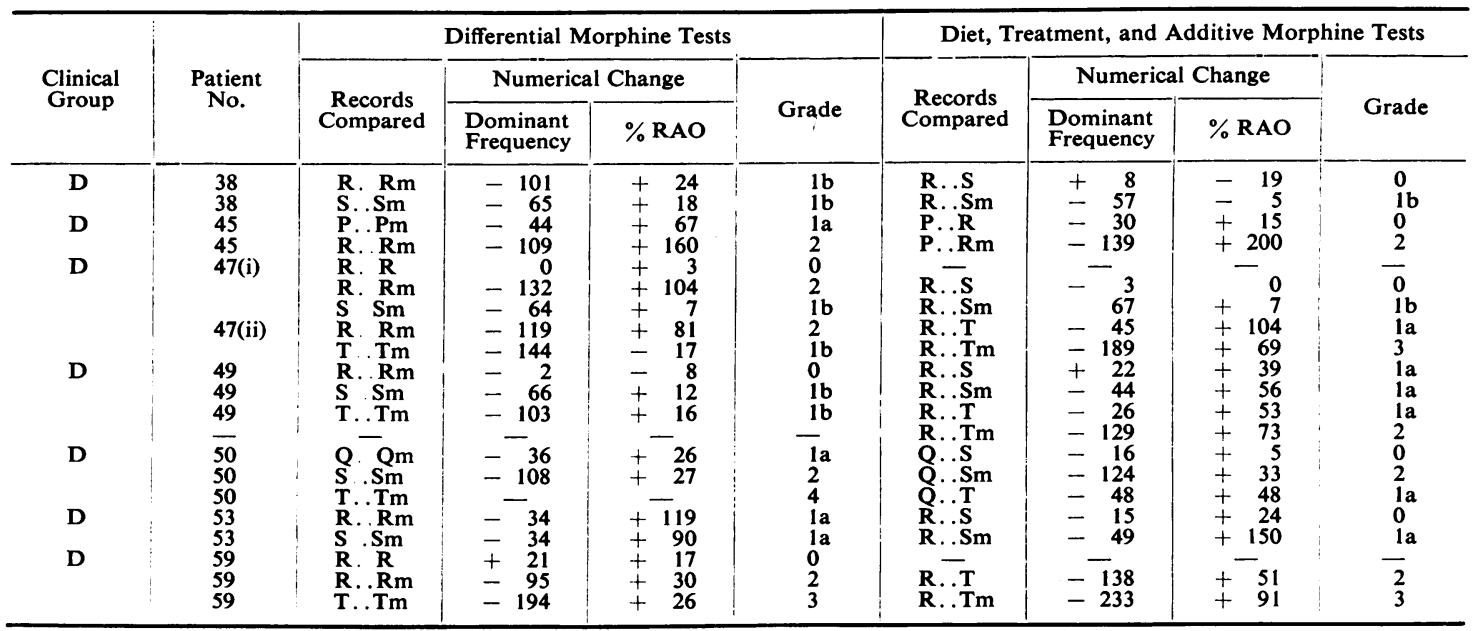

phine, consists of a fall in dominant frequency and percentage increase in RAO, is shown to the right of Table III. The comparison has not been made for patients 8 or 33 since the two morphine tests were several weeks apart, or for patient 36 since the $Q$ record contained too little rhythmic activity for numerical assessment. Since the diet and morphine changes are measured in the same units they can be added and the results, the additive morphine test, are also shown to the right of Table III. If EEG deterioration is produced both by morphine and change of diet the additive test will of course be positive. Its value lies in demonstrating a significant change when the changes produced by the single tests are too small to be considered diagnostic, and like the differential test in making it possible to attribute a non-specific sensitivity to morphine (or encephalopathy) to liver disease.

These differential and additive results in patients in whom the diagnosis is known first support the hypothesis that the response to morphine and encephalopathy are related, and, secondly, suggest that when the diagnosis is in doubt these additional tests may enable a firm EEG diagnosis to be made. In such milder cases the results from the simple morphine test or from the diet alone may be equivocal. Table IV shows full results for seven patients in group $\mathrm{D}$ and these will be considered in more detail.

Case 38 (Fig. 3).-The small changes $\mathrm{R} \ldots \mathrm{Rm}$ and $\mathrm{S}$.. Sm show a more than usual sensitivity to morphine. However, there is no R..S change and the differential and additive morphine tests are both negative. The EEG evidence does not favour the diagnosis of hepatic encephalopathy.
Case 45 (Fig. 3).-The P. . R effect is very small and, alone, is not convincing. P..Pm, although bigger, is also insufficient for a definite diagnosis. However, the diagnosis of hepatic encephalopathy is strongly supported by the positive differential morphine test $(R$. . Rm is greater than P...Pm) and the additive test (P..Rm) which is greater still.

Case 47.-This is a difficult case and the tests were repeated. In the first series when normal diet was contrasted with a high-protein one, there is evidence for encephalopathy since both the morphine tests are positive and the dummy morphine test shows considerable interrecord stability, but there is no deterioration on a highprotein diet alone and the differential and additive tests are negative, thus arguing that the encephalopathy is not hepatic. In the second series ammonium chloride, a stronger provocative agent, was used, and produced some deterioration alone (R.. T) and a positive additive test (R .. Tm) although an equivocal differential test. On the whole the EEG evidence is in favour of hepatic encephalopathy. It is of interest to note the similarity of the $\mathbf{R}$.. Rm changes in the two series.

Case 49.-This is of interest as there was a negative morphine test on normal diet $(\mathbf{R} . . \mathbf{R m})$ but a good differential morphine effect progressively from highprotein diet to ammonium chloride. There are small R..S and R. .T effects and so a good additive morphine test. There is good evidence for hepatic encephalopathy but this is very mild and only likely to produce delirium under considerable provocation.

Case 50.-All three morphine tests are positive with strong differential effects. High-protein feeding produces a very slight and negligible deterioration $(Q \ldots S)$ but ammonium chloride is more effective $(\mathrm{Q} \ldots \mathrm{T})$. The additive morphine effect $(\mathrm{Q} . \mathrm{Tm})$ is irrelevant since T. .Tm has already shown a maximum change. There is strong evidence in favour of hepatic encephalopathy. 

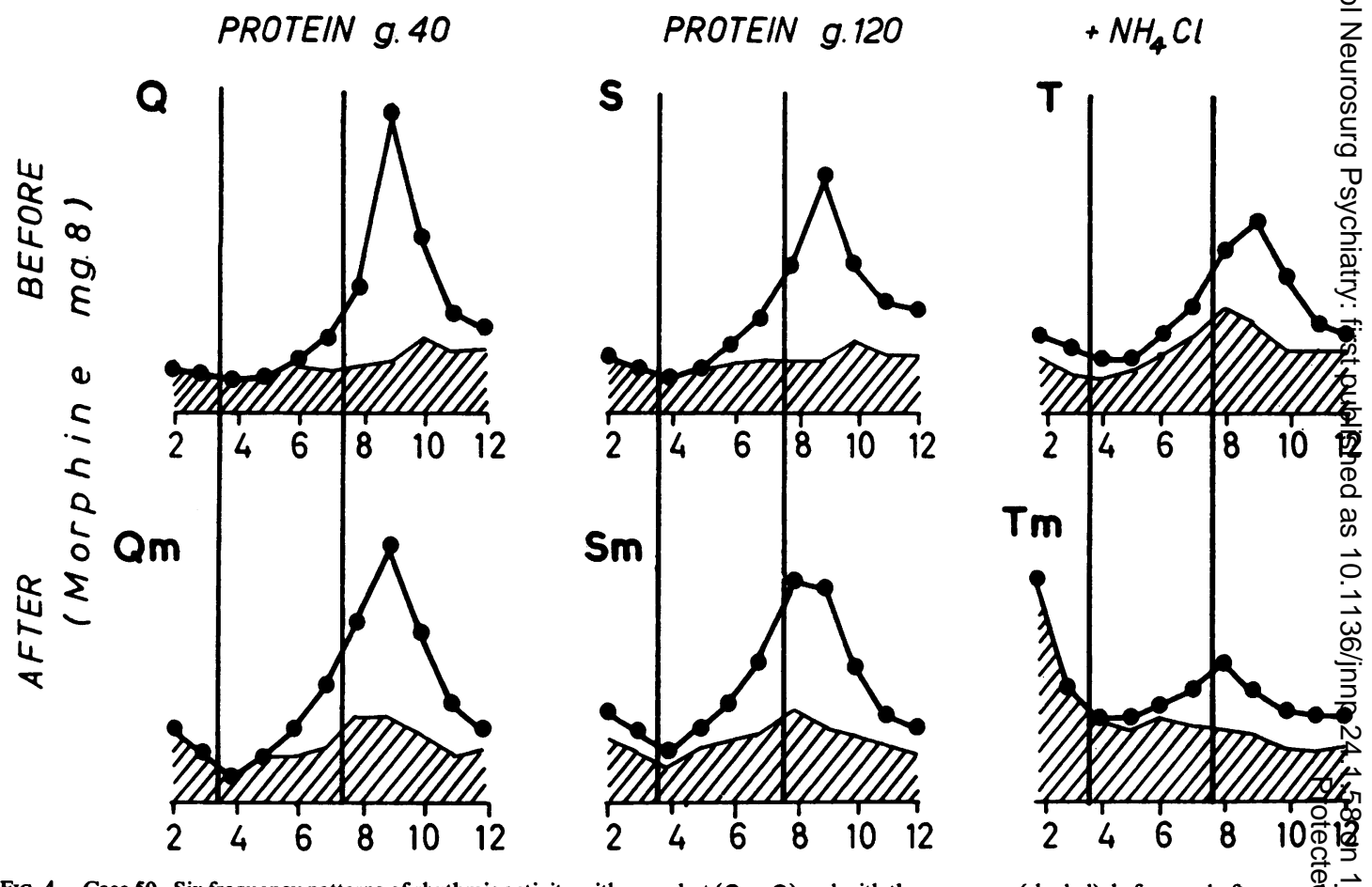

FIG. 4.-Case 50. Six frequency patterns of rhythmic activity with eyes shut ( $-\infty)$ and with the eyes open (shaded), before and after morfhine under different conditions of diet and treatment (see also Table IV).

This case is illustrated (Fig. 4) in the form of frequency patterns.

Case 53 (Fig. 3).-All the changes are very small. Both morphine tests are rositive; the differential test is just negative. Although the effect of a high-protein diet (R..S) is graded 0 there is some change as shown numerically, and, therefore, a positive additive test. The patient may have very mild hepatic encephalopathy.

Case 59 (Fig. 3). - There are two positive morphine tests, no change in the dummy morphine test, a good differential response, and considerable deterioration on ammonium chloride which produces a marked additive morphine effect. There is good evidence for the diagnosis of hepatic encephalopathy.

\section{Discussion}

Simple psychological tests to assess minimal confusion were given at the time of most EEG recordings. These showed good general correlation with the EEG responses to morphine but suggested that the latter were rather more sensitive and reliable. These results will be reported elsewhere (Cang and Laidlaw, in preparation). The clinical problems of the diagnosis of confusion complicating liver disease have been stated very briefly and rather dogmatically and may appear to gastro- enterologists to have been oversimplified. aspect of the work will also be dealt with elsewhere (Read et al., in preparation), and it is sufficient say that the EEG methods described have proved of real clinical value.

A very great deal of EEG work has been done on localized and paroxysmal abnormalities wheres relatively little attention has been paid to the clinical applications of the study of the background rhythmic activity, whether normal or abnorma志 There seem to be two main reasons for this neglect 3

1. Localized or paroxysmal abnormalities, 开 likely to have clinical significance, are usual| clearly apparent in the primary EEG recores whereas the background activity is usually in the form of complex rhythms which are much moire difficult to appreciate or assess.

2. It is comparatively simple to determin whether a localized or an episodic change is sig. nificant since they may be contrasted either in space or in time with what is normal or usual for a pas ticular patient. On the other hand the background activity of a single record may only be considered abnormal if it differs significantly from the bacle ground rhythms of large numbers of controls. Sing the normal range is very wide indeed, significang 
can only be attached to gross variations and the EEG detection of such changes is seldom likely to provide information which could not have been obtained by clinical methods. However, under a number of circumstances, the background rhythmic activity varies with alterations in brain function, and the measurement of changes in this activity for an individual may provide an index of brain metabolism which is more sensitive than clinical examination or psychological testing.

If, therefore, the background activity of the EEG is to yield clinically valuable information, it is necessary in the first place to have a simple and valid method of reducing complex rhythms to a form which can readily be appreciated and compared, and, in the second place, to determine under what circumstances these measures of change in background activity may be considered as indicative of altered cerebral function and not merely as a manifestation of random fluctuation.

The theoretical aspects of different types of analysis have been fully reviewed (Burch, 1959; Kozhevnikov, 1958). Obrist and Henry (1958) carried out a careful comparison of visual and electronic methods and found that both gave essentially similar results, except that like Burch and ourselves they concluded that automatic analysis gave dubious results at low frequencies. We are satisfied that the type of analyser we have used is suitable. It is simple, relatively cheap, requires little adjustment, and is quite sufficiently accurate for ordinary clinical work.

The choice and arrangement of epochs was that found by experience to be the most satisfactory. There must be enough epochs to allow assessment of interepoch variability but the recording must be short enough to anticipate possible deterioration in the patient's condition, since it is very important that any two records being compared should have the same number and arrangement of epochs. The alteration of $S, O$, and $L$ epochs at the beginning of the recording is intended to prevent too much relaxation and may be contrasted with the effect of the three consecutive $S$ epochs at the end. The $L c$ epoch is put at the end for convenience in changing the light pattern. Immediately after shutting the eyes many people show transient faster rhythms (Storm van Leeuwen and Bekkering, 1958) but in normal subjects the rhythms tend to stabilize quickly and a satisfactory reading is obtained by analysing from 15 to 30 seconds after shutting the eyes. The $O$ and $L$ epochs were also taken this time after opening the eyes since the amount of return of rhythmic activity under alerting conditions is a more sensitive index of delirium than the immediate blocking effect of opening the eyes.
A simple adaptation to the analyser allows the activity at individual frequencies to be written out alongside the original record and this is considered valuable. It provides a useful visual check on meter readings, enables change to be assessed in records containing little rhythmic activity, and demonstrates interesting intra-epoch frequency fluctuations. The appearance of high-amplitude delta waves sufficient to dominate the record represents a severe abnormality which can be recognized readily without recourse to electronic frequency analysis and for most purposes no reliance need be placed on the rather unreliable meter readings for very low frequencies.

Detailed numerical comparison between records is based on values calculated for dominant frequency and rhythmic activity under different conditions. In the large series of morphine tests only two measures of deterioration were used, namely, reduction in units of dominant frequency and percentage increase in RAO. This limitation was made first because these values were available for tests throughout the series; secondly, because previous work (Laidlaw, 1959; Read et al., 1959) showed that these changes were found consistently during the early stages of developing delirium; and, thirdly, because more complicated methods of comparison would have yielded no additional useful information. However, in small series or when single pairs of records are being compared a more sophisticated comparison may be useful. Experience has suggested that the following points may be important:

1. The amount of random change from one record to another has been found to vary between patients and to be related to the amount of interepoch variation for that patient. If, therefore, a subject shows little interepoch fluctuation, significance can be attached to smaller inter-record changes.

2. In some subjects there is a tendency for the amount of rhythmic activity with the eyes shut (RAS) to vary from one epoch to another inversely with dominant frequency. In such subjects changes in dominant frequency to be considered significant should be greater than those to be expected from concomitant change in RAS. It may be noted here that with increasing delirium there is a general tendency with fall in dominant frequency for RAS either to remain unchanged or to increase, whereas when a subject becomes drowsy it is usual for dominant frequency and RAS to fall together.

3. RAL and RALc are less subject to spontaneous fluctuations than RAO and in some cases an increase in these values provides a more reliable index of deterioration. However, in other cases 
looking at or counting light patterns produces so much blocking of rhythmic activity that the index is too insensitive.

Measurements are made not of the background activity of a single record but of the difference in such activity between records and are expressed as a degree of deterioration, comparison always being made in the direction in which deterioration may be expected to occur. This method is based on the premise that each individual has, subject to random fluctuations, an optimum or usual record with his own usual values for dominant frequency, RAO, etc., and that factors which produce a general interference with brain metabolism cause the same type of EEG deterioration, namely, reduction in dominant frequency and increase in rhythmic activity under alerting conditions. In as far as these factors are reversible when they are corrected there will be a return to the usual level but over-correction will not produce a supra-optimum record. Previous work (Read et al., 1959) showed that hypokalaemia was one such factor. Low levels of serum potassium might produce a slowing of dominant frequency, restitution to normal would correct this slowing, but hyperkalaemia never produced a level of dominant frequency higher than was usual for the subject. Efron and Kent (1957) suggested that there was an optimum value for carbon dioxide tension and that any marked change, whether an increase or a decrease, produced a reduction in the frequency of the cerebral rhythms. For a patient with known or suspected encephalopathy we do not know whether or not the values for frequency and activity in a resting record represent his pre-morbid optimum. However, the record made under the most favourable circumstances is most likely to approximate to the usual level and should be used as the baseline for comparison whether or not it was the first recorded. It is for this reason that all comparisons in Tables III and IV are made in the direction from $\mathbf{P}$ to $\mathbf{Q}$ to $\mathbf{R}$ to $\mathrm{S}$ to $\mathrm{T}$.

For a measured difference between two records to be considered as indicative of an alteration in brain function it is necessary that it should be greater than that which might occur as a result of random fluctuation. It has been our experience that some patients with encephalopathy show greater fluctuations than normal subjects, fluctuations which if not random are due to causes unknown. It is not, therefore, altogether satisfactory to consider as significant in patients changes which are outside the limits of those found in controls. It is considered better, as in the series described, to contrast the changes between different groups or between records in the same patient under different conditions. When comparing a large number of pairs of records in a big series some form of grading is convenient but $\frac{\text { II }}{1}$ will inevitably be relatively coarse as a measure of change. In that which we have used the limits hate been set widely so that it would be improbable forca change graded other than 0 to be due to random fluctuation, but the converse is not true, and some $\not$; those changes graded as 0 , particularly in subjes showing little interepoch variation, may have bee due to altered brain function. In small series when individual pairs of records are being compared it is recommended that arbitrary grades should no be used but that change between records should considered as significant if appreciably greater the the individual interepoch change or the inter-reco change under conditions when no deterioration could be expected. Thus patients 47 and 9 (Table IV) showed a certain inter-record change $\mathbf{R}$. . R during dummy morphine tests. The changes $\mathbf{R}$. . Rm may be considered significant in contrast $\vec{t}$ these changes.

The system described may be used as a diagnost tool. A patient suffering from an acute gene? interference with brain function which we haje termed 'delirium' is likely even in the very early stages to show EEG deterioration. Even if his record lies within the normal range, it will stootv values for dominant frequency, etc., below $\frac{0}{0}$ his individual optimum. At this stage, when the $\vec{i} \phi$ often no convincing clinical evidence, the diagrosis both of delirium and of its cause may be made gyca therapeutic test in which EEGs are compared 5 fior and before some measure intended to correcto the presumptive cause of the delirium. Thus perhapsa patient with hepatic cirrhosis is confused and it might be thought that this is due to liver disease His EEG (R) is classified as normal. He is give neomycin and the EEG is repeated after throe days $(P)$. The second record may also be classified as normal but there is a difierence between the records and this shows deterioration from P.. suggesting that record $R$ did not represent his usu? record, providing EEG evidence of delirium, and specifying the cause of the delirium as somethipg amenable to treatment with neomycin, making the presumptive diagnosis of hepatic encephalopathy

In many cases, however, what is required is:-a measure of a chronic latent tendency to develop episodes of delirium, what we have termed eicephalopathy. In severe cases a resting EEG may lie below the patient's optimum and there may be room for the therapeutic test. However, in the milder cases, which present the diagnostic problens, the resting record is likely to be at or near the patient's usual level (the encephalopathy is not onfy clinically but electrically latent), and it is in these cases that the use of the type of provocative tests 
which have been described may prove very valuable. We have described the use of non-specific provocations, such as morphine, added to specific provocations, such as increasing the protein in the diet or adding ammonium chloride. There are cases when a non-specific provocation may give a more or less specific diagnosis because of the clinical context. Thus, a marked EEG deterioration with a small dose of morphine in a patient with hepatic cirrhosis, possibly suffering from encephalopathy, provides good evidence not only of encephalopathy but of hepatic encephalopathy. The specific forms of provocation are usually less effective but they may be reinforced by combination with a non-specific provocateur as in the additive morphine test or they may enable significance to be attached to equivocal results from non-specific provocation as in the differential morphine tests.

The general principle underlying the use of provocative tests may be illustrated diagrammatically (Fig. 5) where each circle represents an EEG, the letters written beside having the same meaning as in the clinical investigation reported above, and the distance apart of the circles representing the amount of change from one record to another. Since ER. . ERm and ES. .ESm are greater than CR..CRm and CS. . CSm patient E suffers from greater brain sensitivity to provocative agent ' $\mathrm{m}$ ' than control $\mathrm{C}$, i.e., suffers from encephalopathy. Since ER. . ES is greater
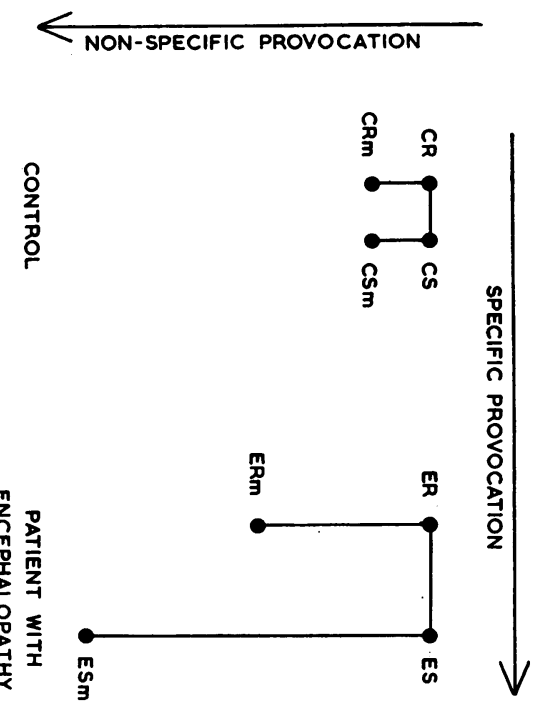

FIG. 5.-Schematic diagram to contrast the effect of provocation (m) on patients without encephalopathy (C) with those with encephalopathy (E) under different conditions ( $R$ and $S$ ) such that the direction of expected deterioration is from $R$ to $S$. $m=$ non-specific provocation, $\mathbf{R}-\mathbf{S}=$ specific provocation than CR..CS and since ES..ESm is greater than ER. .ERm, this encephalopathy is due to a disorder made worse by the provocation represented by the change of condition from $R$ to $S$.

It is suggested that the system of analysis which we have described provides a satisfactory method of measuring changes in the background rhythmic activity of the EEG and enables the significance of these changes to be assessed, and that the production of such EEG changes by appropriate therapeutic or provocative tests may provide a useful diagnostic tool applicable to a variety of conditions in which the metabolism is disordered of those deeply placed structures of the brain, which, it is presumed, play an important part in the control of EEG rhythms and the maintenance of a normal level of consciousness.

\section{Summary}

A method, based on electronic analysis, of assessing the background rhythmic activity of the electroencephalogram is described. The difficulties in obtaining useful information about this activity from a single record are emphasized and a system of quantitative measurement of change between records is described.

Episodes of confusion or alteration of consciousness are defined as 'delirium' and the tendency to develop such episodes as 'encephalopathy'. The EEG is very sensitive to the onset of delirium and the criteria of EEG deterioration along the continuum from normal consciousness to coma are defined.

Certain patients with hepatic cirrhosis may be said to suffer from hepatic encephalopathy in that they are liable to develop episodes of delirium. The application of this EEG method to the diagnosis and assessment of hepatic encephalopathy is described in some detail in order to demonstrate its clinical usefulness.

Patients with mild encephalopathy may show no clinical or EEG abnormalities. In these cases the EEG changes of delirium may be provoked by appropriate measures often without clinical change and at no risk to the patient.

The measurement of change in background rhythmic activity, the significance of such change, and the production of changes by therapeutic and non-specific and specific provocative tests are discussed.

We wish to acknowledge the support and advice of Professor Sheila Sherlock under whose care were the patients described, and to thank the Medical Research Council for personal grants, and Miss R. Harrison, chief dietician, and Miss A. Lees, electroencephalographer. 


\section{REFERENCES}

Adams, R. D., and Foley, J. M. (1953). Res. Publ. Ass, nerv. ment. Dis., 32, 198.

Andrews, H. L. (1941). Psychosom. Med., 3, 399. Brazier, M. A. B., and Finesinger, J. E. (1944). J. clin. Invest.,

Burch, N. R. (1959). Electroenceph. clin. Neurophysiol., 11, 827.

Davis, H., Davis, P. A., Loomis, A. L., Harvey, E. N., and Hobart, G. (1938). J. Neurophysiol., 1, 24.

Dawson, A. M., McLaren, J., and Sherlock, S. (1957). Lancet, 2, 1263.

Dement, W., and Kleitman, N. (1957). Electroenceph. clin. Neurophysiol., 9, 673.

Efron, R., and Kent, D. C. (1957). A.M.A. Arch. Neurol. Psychiat.,
Fagin, I. D., and Thompson, F. M. (1944). Ann. intern. Me⿻ి Greville, G. D., and Heppenstall, Mollie, E. (1950). In Elect encephalography, p. 185, ed. D. Hill and G. Parr. Macdona过. London.

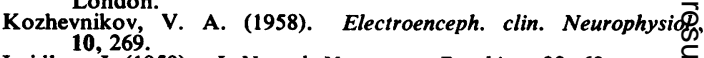

Laidlaw, J. (1959). J. Neurol. Neurosurg. Psychiat., 22, 69. Murphy, T. L., Chalmers, T.C., Eckhardt, R. D., and Davidsoff,

Obrist, W. D., and Henry, C. E. (1958), Electroenceph. clin. Neuk

Read, E. A., Laidlaw, J., Haslam, R. M., and Sherlock, S. (195\%) Clin. Sci., 18, 409.'

Sherlock, S. (1958). Amer. J. Med., 24, 805. Sherlock, S. (1958). Amer. J. Med., 24, 805.
van Leeuwen, W. Storm, and Bekkering, Ir. D. H. (1958). Elecrit.
enceph. clin. Neurophysiol., 10, 563.

Wikler, A. (1954). J. nerv. ment. Dis., 120, 157

\section{THE NOVEMBER (1960) ISSUE}

The November (1960) issue contains the following papers:-

Nerve Fibre Degeneration in the Brain in Amyotrophic Lateral Sclerosis. Marion C. Smith

The Distribution of Lewy Bodies in the Central and Autonomic Nervous Systems in Idiopathic Paralysis Agitann

W. A. den Hartog Jager and J. Bethlem

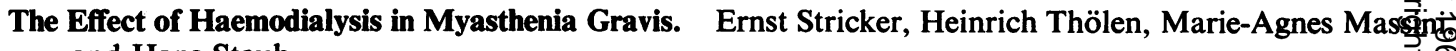
and Hans Staub

Traumatic Epilepsy after Closed Head Injuries. W. Bryan Jennett and Walpole Lewin

A Myopathy Presenting in Adult Life with Features Suggestive of Glycogen Storage Disease. J. MacDona/ Holmes, C. R. Houghton, and A. L. Woolf

Changes in Nerve Conduction with Ulnar Lesions at the Elbow. R. W. Gilliatt and P. K. Thomas

The Clinical Significance of the Sinu-Vertebral Nerve of the Cervical Spine in Relation to the Cervical DisA Syndrome. Ralph B. Cloward

An Experimental Analysis of Confabulation in a Case of Korsakof's Syndrome using a Tachistoscopic Method: Maria Wyke and Elizabeth Warrington

The Effect of Focal Lesions of the Brain upon Auditory and Visual Recent Memory in Man. Lucjan Stepiem and Stanisław Sięrpiński

5-Hydroxyindoles in Mental Deficiency. C. M. B. Pare, M. Sandler, and R. S. Stacey

Society of British Neurological Surgeons: 61st Meeting

Book Reviews

Index to Volume 23

A number of copies are still available and may be obtained from the Publishing Manager, Britis Medical Association, Tavistock Square, W.C.1, price 17s. $6 d$. 